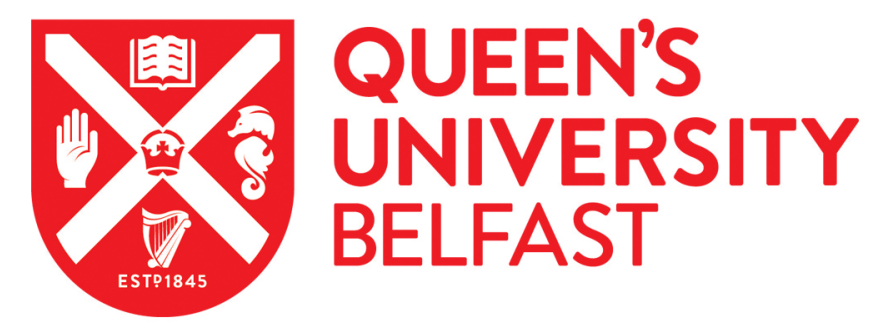

\title{
Proteomic and metabolomic approaches in the search for biomarkers in chronic kidney disease
}

\author{
Cañadas-Garre, M., Anderson, K., McGoldrick, J., Maxwell, A., \& McKnight, A. (2018). Proteomic and \\ metabolomic approaches in the search for biomarkers in chronic kidney disease. Journal of proteomics. \\ http://10.1016/j.jprot.2018.09.020
}

\section{Published in:}

Journal of proteomics

\section{Document Version:}

Peer reviewed version

Queen's University Belfast - Research Portal:

Link to publication record in Queen's University Belfast Research Portal

\section{Publisher rights}

(c) 2018 Elsevier B.V. All rights reserved.

This manuscript version is made available under the CC-BY-NC-ND 4.0 license http://creativecommons.org/licenses/by-nc-nd/4.0/,which permits distribution and reproduction for noncommercial purposes, provided the author and source are cited

\section{General rights}

Copyright for the publications made accessible via the Queen's University Belfast Research Portal is retained by the author(s) and / or other copyright owners and it is a condition of accessing these publications that users recognise and abide by the legal requirements associated with these rights.

Take down policy

The Research Portal is Queen's institutional repository that provides access to Queen's research output. Every effort has been made to ensure that content in the Research Portal does not infringe any person's rights, or applicable UK laws. If you discover content in the Research Portal that you believe breaches copyright or violates any law, please contact openaccess@qub.ac.uk. 
CKD Review Text

INDEX

1 Abstract 2

2 Abbreviations 3

3 Introduction 5

4 Proteomics 5

4.1 Chronic Kidney Disease 6

4.2 Diabetic Kidney Disease 8

4.3 Other Kidney Diseases 9

4.4 Conclusions 9

5 Metabolomics 10

$\begin{array}{lll}5.1 & \text { Chronic Kidney Disease } & 10\end{array}$

5.2 Diabetic Kidney Disease 12

$\begin{array}{lll}5.3 & \text { Other Kidney diseases } & 14\end{array}$

$\begin{array}{lll}5.4 & \text { Conclusions } & 16\end{array}$

6 Concluding Remarks 16

7 Acknowledgments 17

8 Author Contributions $\quad 17$

9 Table Legends $\quad 17$

$\begin{array}{lll}10 & \text { Figure Legends } & 17\end{array}$

11 References 18 


\section{Abstract}

Chronic kidney disease (CKD) is an aging-related disorder that represents a major global public health burden. Current biochemical biomarkers, such as serum creatinine and urinary albumin, have important limitations when used to identify the earliest indication of CKD or in tracking the progression to more advanced CKD. These issues underline the importance of finding and testing new molecular biomarkers that are capable of successfully meeting this clinical need.

The measurement of changes in nature and/or levels of proteins and metabolites in biological samples from patients provide insights into pathophysiological processes. Proteomic and metabolomic techniques provide opportunities to record dynamic chemical signatures in patients over time.

This review article presents an overview of the recent developments in the fields of metabolomics and proteomics in relation to CKD. Among the many different proteomic biomarkers proposed, there is particular interest in the CKD273 classifier, a urinary proteome biomarker reported to predict CKD progression and with implementation potential. Other individual non-invasive peptidomic biomarkers that are potentially relevant for CKD detection include type 1 collagen, uromodulin and mucin-1. Despite the limited sample sizes and variability of the metabolomics studies, some metabolites such as trimethylamine $\mathrm{N}$-oxide, kynurenine and citrulline stand out as potential biomarkers in CKD. 


\section{Abbreviations}

$\begin{array}{ll}\text { A1AT } & \alpha_{1} \text {-antitrypsin } \\ \text { ADMA } & \text { asymmetric dimethylarginine } \\ \text { ADPKD } & \text { autosomal dominant polycystic kidney disease }\end{array}$

Ang II angiotensin-II

ArMORR Accelerated Mortality On Renal Replacement

ATI acute transplant injury

ATN acute tubular necrosis

AUC area under the curve

$\beta 2 \mathrm{MG} \quad \beta_{2}$-microglobulin

CE capillary electrophoresis

CKD chronic kidney disease

CKDGen Chronic Kidney Disease Genetics Consortium

CVD cardiovascular disease

DKD diabetic kidney disease

DM diabetes mellitus

eGFR estimated glomerular filtration rate

eGFRcrea estimated glomerular filtration rate based on creatinine levels

eGFRcys estimated glomerular filtration rate based on cystatin C levels

ESRD end-stage renal disease

FHS Framingham Heart Study

FinnDiane Finnish Diabetic Nephropathy Study

FSGS focal segmental glomerulosclerosis

GFR glomerular filtration rate

GWAS genome-wide association study

HbA1c haemoglobin A1c

HDL high density lipoprotein

HODE 13-hydroxyoctadecadienoic acid

IgAN IgA nephropathy

KDIGO Kidney Disease: Improving Global Outcomes

KORA Cooperative Health Research in the Augsburg Region 
CKD Review Text

LDL low-density lipoprotein

LN lupus nephritis

MCD minimal change disease

MGN membranous glomerulonephritis

MUTHER Multiple Tissue Human Expression Resource Consortium

NMR nuclear magnetic resonance

MS mass spectrometry

PREVEND Prevention of REnal and Vascular End-stage Disease

PTH parathyroid hormone

RNA ribonucleic acid

ROC receiver operator characteristics curve

$\mathrm{SCr} \quad$ serum creatinine

SDMA symmetric dimethylarginine

SHIP Study of Health in Pomerania

SLE Systemic lupus erythematosus

T1DM type 1 diabetes mellitus

T2DM type 2 diabetes mellitus

TMAO trimethylamine $\mathrm{N}$-oxide

UACR urinary albumin-to-creatinine ratio

UAE urinary albumin excretion

VLDL very-low-density lipoprotein 


\section{Introduction}

Chronic kidney disease (CKD) is defined by the 2012 Kidney Disease: Improving Global Outcomes (KDIGO) Clinical Practice Guideline as sustained abnormalities of kidney structure or function (for $>3$ months), mainly indicated by albuminuria (excess albumin excretion in urine) or a glomerular filtration rate (GFR) lower than $60 \mathrm{~mL} / \mathrm{min}$ per $1.73 \mathrm{~m}^{2}$, respectively[1]. CKD is a rapidly increasing major clinical problem that affects up to $17 \%$ of the adult population worldwide and more than $20 \%$ of those over 65 years old[2-4]. There are multiple causes of CKD linked to common disorders, such as diabetes mellitus (DM), metabolic syndrome and hypertension; less common primary kidney diseases include autoimmune disorders such as IgA nephropathy (IgAN), membranous glomerulonephritis (MGN) and lupus nephritis (LN), and genetic disorders, such as autosomal dominant polycystic kidney disease (ADPKD)[1].

The KDIGO guidelines recommend using serum creatinine ( $\mathrm{SCr}$ ) for the evaluation of GFR with a GFR estimating equation (estimated GFR, eGFR) for initial assessment (Figure 1)[1]. However, SCr based equations (eGFRcrea) are less accurate under specific circumstances (older people, individuals at the extremes of body-mass index, different ethnicities), and a cystatin C based equation (eGFRcys) or a clearance measurement for confirmatory testing are then needed[1]. These GFR measurement methods and markers are not exempt from limitations either. The gold standard methods are either invasive (urinary clearance) or expensive and not widely available (inulin); alternative GFR measurements to these also have a variety of drawbacks, including wide inter-individual variability, potential for allergic reactions, and special handling issues related to radioactive substance [1]. Cystatin $\mathrm{C}$ levels are increased by inflammation, steroid drugs and thyroid disease, challenging the use of eGFRcys equations in these circumstances[5]. Kidney damage can also be evaluated through the measurement of albuminuria or proteinuria, markers associated with rapid progression but that are not always present in CKD or may vary in different CKD stages[1].

There is therefore an increasing need to find new serum and urine biomarkers capable of estimating the risk of CKD in healthy individuals and in patients with pathological conditions that predispose them to CKD. These new kidney biomarkers would augment the use of $\mathrm{SCr}$ and urinary albumin excretion (UAE) in the prediction of outcomes in individuals with CKD and helping in the management of renal disease (Figure 1). Over the last decade, many studies have attempted to find alternatives to the conventional clinical kidney biomarkers with increasing attention being given to the proteomic or metabolomic analysis of serum and urine samples (Figure 2). This review tries to summarise the more important results of this quest for novel proteomic and metabolomic biomarkers for CKD in humans. The search engine used for this literature review was PubMed. The literature search criteria applied were all the possible combinations of "chronic kidney disease", "diabetic kidney disease", "glomerulonephritis", and the MeSH terms "Renal Insufficiency, Chronic" or "Kidney Diseases" with the MeSH terms "Proteomics" or "Metabolomics". Only studies in humans written in English or Spanish focused on proteomic or metabolomic markers were included. References of the selected articles were manually searched and added to the pool of reviewed articles.

\section{Proteomics}

The full set of proteins expressed by an organism is referred to as the proteome, a term that can also reflect the content of proteins produced in a specific cell or tissue, at a certain time [6]. Proteomics is the study of the proteome, including the low molecular weight proteome fractions (peptidome), and can be approached using a variety of different laboratory techniques, such as two-dimensional gel electrophoresis, capillary electrophoresis coupled electrospray ionisation - mass spectrometry (CE- 
ESI-MS), liquid chromatography coupled mass spectrometry (LC-MS), and matrix-assisted laser desorption/ionization mass spectrometry (MALDI-MS) [7-9].

Under normal physiological conditions, the urine should contain only small levels of low molecular/middle weight proteins; this protein content changes in pathological situations [9]. Noninvasive detection of renal disease using urinary proteomics is becoming a very important area of research. Numerous investigations using proteome analysis for early detection and improved risk stratification of patients with CKD have been carried out in the past decade, many of them including large numbers of patients $[9,10]$. Urine has been the preferred choice of biospecimen to detect changes in different peptide levels among patients with CKD and various different individual renal diseases, such as diabetic kidney disease (DKD), IgAN, and ADPKD (Table 1).

\subsection{Chronic Kidney Disease}

The presence in the urine of several proteins or changes in their levels have been proposed as noninvasive urinary biomarkers for CKD in numerous European populations (Table 1).

In 2010, a human urinary peptidome panel, composed of 273 CKD-specific biomarkers, compiling data from 230 patients with various biopsy-proven kidney diseases and 379 healthy subjects (training set), was identified using CE-MS [11]. A sensitivity of $98.7 \%$ and a specificity of $100 \%$ was reported, with an area under the curve (AUC) of 1.000 for the diagnosis of CKD. These findings were replicated in an independent cohort of 110 CKD patients and 34 healthy individuals (test set), showing a sensitivity of $85 \%$ (95\%Cl:77.5-91.4) and specificity of 100\% (95\%C: 89.6-100.0), with AUC=0.955 [11]. A similar performance of the CKD273 classifier was furtherly confirmed in urine samples from 62 type 2 diabetes mellitus (T2DM) macroalbuminuric patients with CKD and 75 normoalbuminuric T2DM controls (AUC $=0.96$ ) [7]. The CKD273 classifier was furtherly validated in a multicentre study including 165 T2DM patients from nine different institutions [12]. Main components of the CKD273 classifier in CKD patients include fragments of different collagens, kidney-specific proteins (uromodulin, sodium/potassium-transporting ATPase $\gamma$ chain, membrane-associated progesterone receptor component 1 , etc), blood proteins (serum albumin, $\alpha_{1}$-antitrypsin (A1AT), haemoglobin $\alpha$ chain, fibrinogen $\alpha$ chain, etc), among other secreted proteins [11].

The utility of CDK273 classifier for the management of CKD patients has been investigated in many studies [7,12-20]. The CKD273 classifier has been demonstrated to improve the performance of UAE in predicting $D K D$ ( $A C_{\mathrm{CKD}_{273}}=0.93$ vs $\left.A U C_{\mathrm{UAE}}=0.67\right)$ [14], transition in albuminuria stage ( $A \cup C_{\mathrm{CKD} 273}=0.94$ vs $A \cup C_{\text {UAE/ } / G F R}=0.91$ ) [19], CKD progression [16-18,21], progression to end-stage renal disease (ESRD) (general linear model, F-test $=19.44$; $p<0.0001$ ) [15] and loss of GFR at an early CKD stage (eGFR $\left.>70 \mathrm{~mL} / \mathrm{min} / 1.73 \mathrm{~m}^{2}\right)(p<0.05)$ [20]. It has been suggested that the pattern of various modified collagen fragments in the urinary CKD273 classifier may indicate extracellular matrix changes [20], a hallmark of renal disease that is present from the early stages of CKD [22]. Among the other peptides present in the CKD273 panel, both serum albumin fragments and A1AT were increased in the urine of individuals with moderately advanced disease stages (eGFR $40-69 \mathrm{~mL} / \mathrm{min} / 1.73 \mathrm{~m}^{2}$ ) from a sample of 394 individuals who had a decline in eGFR of $>5 \mathrm{~mL} / \mathrm{min} / 1.73 \mathrm{~m}^{2} /$ year [20]. Patients with CKD progression (progressors) also had decreased levels of collagen and uromodulin fragments in the urine. The CKD273 classifier also demonstrated greater stability in predicting renal function in CKD patients [20]. In a small study in Norwegian patients, the 18 CKD stage 4-5 cases also showed reduced excretion of collagen fragments types I-III and uromodulin compared to 17 healthy controls [23]. Increased levels of $\alpha$-2-HS-glycoprotein [19], blood and inflammation peptides (fibrinogen, apolipoproteins, haemoglobin) have also been found in CKD patients as part of the CKD273 classifier [24]. 
The CKD273 classifier has also proven its utility to evaluate response to irbesartan [13] and spironolactone [25] therapy in clinical trials. Currently, the CKD273 classifier is being assessed to establish if it can identify diabetic patients with a high-risk of developing albuminuria in all participants $(\approx 3500)$ of a prospective multicentre clinical trial, designed as a randomised double-blind placebocontrolled intervention (spironolactone) in DKD patients from nine European countries (NCT02040441, [18]). Furthermore, the US Food and Drug Administration (FDA) has issued a letter of support to encourage the further development of the urinary CKD273 biomarker panel of peptides as a prognostic tool to be used in combination with albuminuria, serum creatinine and other current measures in early phase clinical trials in DKD, to identify early stage disease patients with high-risk of CKD progression [26]. The cost-effectiveness of screening T2DM patients for CKD progression using the CKD273 classifier has been recently evaluated using a decision-analytic Markov model that provided intensified therapy including additional antihypertensive therapy, ACE inhibitors or spironolactone to patients classified as high-risk for complications (DKD, kidney transplantation, graft failure, dialysis and death attributable either to CKD or cardiovascular diseases) [27]. Annual screening with the CKD273 classifier was more costly than UAE (incremental costs of $€ 3,053$ per patient), but may have resulted in improved care, since patients had better survival and gained 0.13 qualityadjusted life years (QALYS), mainly due to slower CKD progression, fewer diabetic complications and overall better quality of life [27]. The incremental cost-effectiveness ratio (ICER) of the CKD273 classifier screening in all patients was $€ 23,903$ per QALY gained compared to UAE, notably lower than current government thresholds for QALYs [27]. The impact of the CKD classifier was notably higher in T2DM patients at high-risk of developing CKD, less costly and more effective in relation to QALYs gained, hence cost-saving (reduction of $€ 700$ and gain of 0.17 QALYs per patient), whereas it was not cost-effective in low-risk patients (ICER: €73,140 PER QALY gained) [27]. Recently, the urinary proteomic classifier CKD273 was reported to provide improved prognostic information on clinical outcomes in 155 patients with T2DM and confirmed microalbuminuria, being associated with higher mortality after adjustment for age, sex and other established cardiovascular and renal biomarkers in a Cox regression model $(p=0.048)[28]$.

Consistent with the CKD273 classifier, decreased levels of collagen fragments have been a common finding in the urine of CKD patients in other studies. Both collagen type I and uromodulin fragments were in lower abundance in 49 patients (26 DKD and 23 with other CKD aetiologies), whilst beta-2microglobulin, apolipoprotein $\mathrm{Al}$ and protein S100-A9 fragments were in higher abundance in CKD stage 4-5 patients [29]. Plasma fibrinopeptide-A, phosphorylated fibrinopeptide-A, prolinehydroxyproline dipeptide, and urine beta-2-microglobulin, apolipoprotein Al and protein S100-A9 fragments have been found in higher abundance in the urine from patients with advanced CKD, whereas collagen type I alpha 1 and uromodulin had lower levels in urine [30,31].

Other urinary peptidome panels have been described for different renal diseases. A panel composed by 384 peptide fragments ( $78 \%$ derived from different types of collagen) was identified from urine samples obtained from 376 individuals with renal disease. This 384 peptide fragment panel identified a group of patients who had more stable kidney function over time, allowing a less aggressive treatment regimens to be provided [32]. The urinary proteome of 805 participants in the FLEMENGHO study showed that peptide fragments from mucin-1 subunit $\alpha$, collagen I and III, and fibrinogen $\alpha$ chain were all inversely correlated to eGFR and its change over time, with the risk of progressing to CKD being significantly linked with mucin-1 subunit $\alpha$ and collagen I fragments [33]. The urinary mucin1 subunit $\alpha$ fragment was the strongest peptidomic correlate of a reduced eGFR [33]. Changes in eGFR were significantly associated with the levels of four proteins contained in the high density lipoprotein (HDL) particles of a cohort of 509 CKD patients. Patients with kidney failure exhibited higher levels of retinol-binding protein 4, apolipoprotein C-III, versus lower apolipoprotein L1 and vitronectin [34]. In 
a small sample of seven CKD stage 5 patients, albumin, apolipoprotein A-II and complement factor C8 $\gamma$ - and $\beta$-chains were shown differentially depleted compared to seven matched healthy controls [35].

\subsection{Diabetic Kidney Disease}

Diabetic kidney disease (DKD) is a major complication of diabetes. Its early detection could lead to delay or even prevention of the need for renal replacement therapy, since targeted clinical management could be introduced at the earliest stage of DKD [36].

Urinary proteomics might also allow non-invasive assessment of DKD, identifying those at risk of DKD at an early stage. As described in the previous section, the proteome CKD classifier, which includes collagen fragments, $\alpha$-microglobulin, $\beta_{2}$-microglobulin ( $\left.\beta 2 M G\right), A 1 A T$, uromodulin, among other peptides, has proven to be a promising biomarker panel for detecting individuals with T2DM at highrisk of developing CKD [14]. Collagen fragments appear to be important biomarkers for the detection of DKD. Urine samples of 16 initially normoalbuminuric diabetic patients with type 1 diabetes and 19 with type 2 diabetes showed higher levels of collagen fragments, acting as early biomarkers of DKD some 3-5 years before macroalbuminuria onset [14]. A decrease in urinary collagen fragments was shown in the urine before albumin excretion increased [14]. Collagen alpha-1(I) and collagen alpha-5 (IV) were also increased in individuals with T2DM, persons with CKD not due to diabetes, and patients with T2DM and DKD compared to 10 healthy controls [37]. Collagen has also been suggested to be a more specific biomarker than urinary albumin in other proteomic panels, like the one developed in 64 individuals with T2DM with nephropathy and 81 persons with T2DM and no nephropathy [38]. In 305 individuals, a panel of 40 urinary biomarkers was identified that could discriminate healthy individuals from patients with diabetes (89\% sensitivity, 91\% specificity) [39]. An additional panel of 65 peptides also distinguished DKD from persistent normoalbuminuria (93\% sensitivity, 97\% specificity) [39]. Again, a majority of these biomarkers were fragments of collagen type I, but in this case, its excretion was reduced in patients with diabetes or DKD [39].

Uromodulin, present in the CKD273 classifier, was also downregulated in nephropathy cases, in a study including persons with T2DM, non-diabetic renal disease, T2DM with DKD compared to healthy controls [37], although it was not differentially distributed in T2DM progressing to DKD [40]. A1AT, also part of the CKD273, showed a significant increase in six type 1 diabetes mellitus (T1DM) and 13 T2DM patients compared to 19 healthy controls [41].

In a small discovery sample of eight normoalbuminuric T2DM patients (stable group: four with no change in $\mathrm{SCr}$ and progressor group: four with a minimum 60\% increase in $\mathrm{SCr}$ during follow-up), haptoglobin was identified as the most abundant protein in the urine among those proteins expressed only in one group [40]. Haptoglobin also proved to be the best urine biomarker for prediction of early renal function decline using seven proteins tested in a small verification group composed by 12 progressors and 18 stable patients (no increase in serum creatinine over 6 years) [40]. Using urinary haptoglobin along with the urinary albumin-to-creatinine ratio (UACR) in 204 T2DM patients without significant kidney disease at the beginning of the study, the model improved predictive ability, providing a useful way to identify T2DM patients who are at risk of developing DKD [40]. Haptoglobin and A1AT, among others were also associated with glomerular dysfunction in T1DM patients [42].

In 65 individuals with T2DM, increased $\beta 2 M G$ and excretion of ubiquitin were higher in patients with DKD compared to those without DKD [43]. Urinary $\beta 2$ microglobulin has been shown to be consistently increased in patients with DM regardless of nephropathy when compared to healthy controls in several studies [43-45]. Alpha1-microglobulin has also been increased in the urine of patients with 
DKD, as observed in 100 persons with T2DM compared to 20 healthy controls [46], and in 14 individuals with T1DM and 92 individuals with T2DM compared to 50 healthy controls [47]. UbA52, a ubiquitin ribosomal fusion protein, was selectively excreted in the urine of $38 \mathrm{DM}$ with micro- or macroalbuminuria patients $(p<0.00008)$ when compared to $45 \mathrm{DM}$ patients without micro- or macroalbuminuria, 34 patients with macroalbuminuria caused by non-diabetic disease and 45 healthy controls [44].

Urinary E-cadherin was upregulated in the urine of 24 T2DM patients compared to 8 healthy controls, despite its immunohistochemical expression being downregulated in renal tubular epithelial cells from renal biopsies of patients with DKD compared to healthy controls [48].

Other proteins have been found differentially distributed in the urine of DM patients, that may be of interest in relation to DKD. The upregulation of 1B-glycoprotein, zinc-2-glycoprotein, 2-HSglycoprotein, vitamin D-binding protein, calgranulin B, A1AT and hemopexin was observed in 33 T2DM patients compared to nine healthy controls [49]. Those with DKD all appeared to have greater MMP9/neutrophil gelatinase-associated lipocalin, aminopeptidase $N$, azurocidin and kallikrein 1 activity compared to healthy controls [50]. In patients with T1DM, inositol pentakisphosphate 2-kinase, zona occludens 3, and FAT tumor suppressor 2 were upregulated [51]. Twenty-four patients with T1DM both with and without microalbuminuria, had an increase in megalin and cubilin compared to 12 healthy controls [52]. In T2DM, Ig $\mathrm{K}$ chain $\mathrm{C}$ region, Ig $\mathrm{K}$ chain $\mathrm{V}$-II region Cum, Ig $\mathrm{k}$-chain V-III region $\mathrm{SIE}$, carbonic anhydrase 1 , plasma retinol-binding protein, $\beta_{2}$-glycoprotein 1 were all significantly increased in persons with T2DM or individuals withT2DM and DKD, compared to healthy controls [45].

\subsection{Other Kidney Diseases}

The urine proteome analysis is an area of interest for various kidney disorders, such as LN or ADPKD. Angiotensin-II (Ang II)-regulated proteins showed a higher excretion rate in (non-ADPKD)-CKD patients, versus lower levels in ADPKD patients. However, the expression of Ang II-regulated proteins at the mRNA level was significantly increased in kidney cysts compared to normal tissue [53].

In a study with 88 systemic lupus erythematosus (SLE) patients and 60 controls, urinary alpha-1 antichymotrypsin, retinol binding protein and haptoglobin were identified as potential biomarkers for LN activity [54].

\subsection{Conclusions}

Multiple studies of urine proteomes have been undertaken exploring whether the proteome analysis can aid diagnosis, disease classification, and the monitoring of CKD progression. Among many different proteomic biomarkers proposed, there has been most focus on the CKD273 classifier which has predicted CKD progression in several separate studies. Arguably, this urinary proteome biomarker panel has the potential of being used in clinical practice. It may prove to be more cost-effective than monitoring UAE rate in diabetic patients [27], prompting its availability as an in vitro diagnostic test in Germany for the early detection of CKD in diabetic patients [24], and recent support from the FDA for further evaluation and studies to establish its clinical utility [26]. Type 1 collagen has been identified as one of the most promising individual urinary biomarkers. Its downregulation is significantly associated with CKD. Other non-invasive peptidomic biomarkers potentially relevant for the detection of CKD are uromodulin and mucin-1. Increased expression of $\alpha$-2-HS-glycoprotein and fibrinogen $\alpha$ chain have also been proposed as CKD biomarkers, however this requires confirmation in further studies. 


\section{Metabolomics}

Metabolomics is the non-targeted measurement of changes in all of the endogenous and exogenous low-molecular-weight metabolites produced by the body in biofluids like urine, plasma or serum, providing a functional fingerprint of the current physiological and pathophysiological status of a living organism $[55,56]$.

The two most common technologies to evaluate metabolomic profiles are proton nuclear magnetic resonance spectroscopy and mass spectrometry (MS), the latter usually coupled with separation techniques such as gas chromatography, $\mathrm{CE}$, high/ultra performance liquid chromatography or direct flow injection analysis without prior separation (Table 2).

The metabolomics of kidney diseases has been increasingly investigated in the past 10 years, with over 60 articles published addressing the different profiles found in patients with CKD, DKD, and primary glomerulopathies (Tables 3-6). Although most of the studies have been performed in small populations, important efforts have been made to investigate the role of different metabolomic profiles in development of kidney disease, decrease of kidney function and disease progression in larger populations from the Framingham Heart Study (FHS) [57], the Cooperative Health Research in the Augsburg Region (KORA) [58], the TwinsUK Study [59], the Finnish Diabetic Nephropathy Study (FinnDiane) [60-62], and The Study of Health in Pomerania (SHIP) [63]. Tables 3-6 show a nonexhaustive list of the most recent works published, including their principal findings.

\subsection{Chronic Kidney Disease}

Table 3 shows metabolomic studies in CKD. The association of different plasma metabolite profiles with the incidence of CKD was investigated by Rhee et al. in 1,311 participants from the FHS [64]. A multimarker panel of five metabolites was constructed by logistic regression, including kynurenic acid, xanthosine, 5-hydroxyindoleacetic acid, kynurenine, and citrulline. Citrulline has been confirmed to be associated with CKD progression and/or eGFR decrease in two small studies in 77 and 30 Caucasian CKD patients, respectively $[31,65]$. The work by Rhee et al. confirmed that serum levels of kynurenic acid and kynurenine, tryptophan catabolites of the kynurenine pathway, increase with CKD development and severity, as previously had been proposed in a small case-control study including 80 Caucasian individuals [66]. Alterations in the kynurenine pathway have also been associated with decreased eGFR and advanced CKD in several studies conducted in 69 Asian patients [67], Caucasians (two studies, 49 and 80 patients, respectively) [30,66] and 1104 African Americans [68].

In a recent study in 347 Asian CKD patients and 56 healthy controls, matched for age and sex, serum levels of creatinine, pyruvate, formate, leucine, urea, trimethylamine oxide (TMAO), and tyrosine could discriminate healthy controls from all subjects with CKD [69]. Formate and tyrosine were important metabolites to discriminate CKD patients without DM from the healthy controls, whereas arginine, $\mathrm{N}$-acetyl-glycoprotein, and very-low-density lipoprotein (VLDL)/low-density lipoprotein (LDL) $\mathrm{CH} 3$ were significant metabolites in CKD patients with DM [69]. Although the accuracies to predict CKD, CKD without DM, or CKD with DM ranged between 57-66\%, this study has confirmed TMAO as an important predictor of CKD risk. Increased risk of CKD had been previously described in patients with higher levels of urine and plasma TMAO in two small studies including 73 and 14 patients, respectively $[70,71]$. Higher TMAO levels have also been associated with coronary atherosclerosis burden, long-term mortality and decrease of kidney function (eGFR) in CKD patients [72,73].

Lower levels of the natural amino acid derivative 5-oxoproline, a glutamate precursor in the glutathione cycle, have recently been associated with the development of CKD as part of two metabolite panels composed by 2 and 7 entities, respectively, in serum samples from 1,921 African 
American patients [74] and urine from 73 Caucasians [70]. A model incorporating a combination of six metabolites (including C-mannosyltryptophan, pseudouridine, and $\mathrm{N}$-acetylornithine) and clinical parameters showed a predictive ability for incident CKD, as measured by the AUC, of 0.84 (Cl 95\% $_{0}$ : 0.800.88 ) in a study comprising patients from the KORA (1735) and TwinsUK (1164) cohorts [75].

Higher levels of four acylcarnitines (oleoylcarnitine, linoleylcarnitine, palmitoylcarnitine, and stearoylcarnitine) were found to be predictors of cardiovascular death in incident ESRD dialysis patients from the Accelerated Mortality on Renal Replacement (ArMORR) study $(P<0.0003)$ [76].

The association of metabolite profiles with renal function has been the focus of many studies. A nontargeted metabolomics approach has recently been used to identify novel markers capable of estimating kidney function in a large population-based study including 1735 Augsburg patients from the KORA cohort and 1,164 female patients from the TwinsUK Study [75]. Higher concentrations of six metabolites were associated with lower eGFRcrea and higher CKD prevalence: pseudouridine, Cmannosyltryptophan, $\mathrm{N}$-acetylalanine, erythronate, myo-inositol, and $\mathrm{N}$-acetylcarnosine. In particular, C-mannosyltryptophan showed the highest correlation with both eGFRcrea and eGFRcys, along with annual eGFRcrea decline $(p=0.03)$ [75], which had been previously associated with elevated baseline levels of serum spermidine in 1,104 patients from the KORA cohort $\left(p=5 \cdot 8 \cdot 10^{-7}\right)$ [68]. The analysis of 3,011 Augsburg patients from the KORA cohort and the meta-analysis including 984 additional female patients from the TwinsUK Study also identified 22 metabolites belonging to the class of acylcarnitines associated with decreased eGFRcrea, with higher serum concentrations of glutarylcarnitine having the strongest association $\left(p_{\text {pooled }}=1.8 \cdot 10^{-69}\right.$ ) [77]. Higher plasma levels of acylcarnitines have also been related to development and progression of CKD in 49 Caucasians [30] and with cardiovascular mortality in 200 haemodialysis patients (oleoylcarnitine) from the ArMORR cohort [76].

Other metabolites inversely correlated with eGFR levels in CKD patients, consistently found in several studies, are trimethylamine-N-oxide (TMAO), kynurenine, ornithine, citrulline, asymmetric dimethylarginine (ADMA), and 3-indoxyl sulphate [30,31,65-67,72,73,78].

Several studies have identified metabolites that may be useful as markers for CKD progression and stratification of kidney function. Several components of the kynurenine pathway, a metabolic pathway leading to the production of nicotinamide adenine dinucleotide (NAD+) from tryptophan catabolism, have been identified as potential markers of CKD progression in plasma and urine. Serum or plasma levels of kynurenine, hydroxy kynurenine, kynurenic acid, and quinolinic acid increased with CKD severity in Asian and Caucasians $[30,66,67]$.

Citrulline and ornithine, intermediates in the urea cycle, have also been found altered in plasma and urine of 77 and 30 Caucasians CKD patients [31,65]. Plasma levels of citrulline and ADMA, a metabolic by-product created in protein methylation and related to L-arginine, are elevated in advanced CKD patients $[30,31,65]$. On the other hand, urinary excretion of citrulline was also enhanced in advanced CKD patients (stages 4 and 5), whereas dimethylarginine concentrations were lower [30,65]. Ornithine levels were lower in plasma from stage 3 and 4 CKD patients compared with stage 2 CKD [31].

Different peptide profiles are associated with CKD progression. Plasma fibrinopeptide-A, phosphorylated fibrinopeptide-A, proline-hydroxyproline dipeptide, and urine beta-2-microglobulin, apolipoprotein Al and protein S100-A9 fragments have been found in higher abundance in advanced CKD patients, whereas collagen type I alpha 1 and uromodulin showed lower levels in urine [30,31].

TMAO, a product of the metabolism of dietary L-carnitine and choline, has been found to be elevated in the serum of 104 CKD patients with variable kidney function, ranging from normal function to ESRD; serum TMAO levels were notably reduced after transplantation [72]. Choline, phosphorylcholine, 
glycerphosphorylcholine and betaine, among others, showed lower levels in the serum of 80 CKD Asian patients matched for age, sex, and ethnicity with 28 healthy controls [79].

A panel of 16 metabolites demonstrated a 2.0- to 8.0-fold higher risk of developing worse outcomes (ESRD requiring replacement therapy and all-cause mortality) in 112 Asian CKD patients [80]. This panel showed good predictive values in the presence (4-oxopentanoate, glucoronate, 2hydroxyisobutyrate, 5-oxoproline, pimelate, $\mathrm{N}$-acetylneuraminate, 3-methylhistidine, phthalate, tryptophan, hippurate, and 3-hydroxy-3-methylglutarate), absence (citramalate and 2,3pyrinedicarboxylate), or regardless of diabetes (isethionate, saccharate, trimethylamine $\mathrm{N}$-oxide, cytidine, gluconate, guanidinosuccinate, and uridine) [80].

Four large population-based studies have attempted to find metabolomic signatures associated with gene markers in CKD $[59,75,81,82]$.

In 2011, Suhre et al. analysed the serum metabolic profile of 1,768 participants of the German KORA F4 study and 1,052 of the British TwinsUK study [59]. They identified a total of 23 new and 14 known independent loci at genome-wide significance in the meta-analysis, which were associated with a clinical endpoint in 15 loci, including cardiovascular disease (CVD), kidney disease, Crohn's disease, gout, cancer, pharmacogenomics, and predisposing risk factors for diabetes and CVD. Regarding detoxification and kidney function, they found a highly-significant association of variation at the NAT8 locus with $\mathrm{N}$-acetylornithine [59]. In particular, higher levels of $\mathrm{N}$-acetylornithine were correlated with lower eGFR in both studies ( $\mathrm{p}_{\text {KORA }}=7.6 \cdot 10^{-4}, \mathrm{p}_{\text {Twins }}=3.6 \cdot 10^{-8}$ after adjusting for age and gender). Thus, the risk allele of NAT8 gene polymorphism would be associated with higher $\mathrm{N}$-acetylornithine concentrations [59]. In other genome-wide association study (GWAS) of metabolic traits in human urine, the same authors tested 59 metabolites in urine from 862 male participants in the populationbased SHIP study. The results were furtherly replicated in 1,039 additional patients of the same study and 992 samples from the independent KORA study. They found a panel of five single nucleotide polymorphisms: rs37369 (AGXT2), rs4921914 (NAT2), rs830124 (WDR66), rs8101881 (SLC7A9), and rs17279437 (SLC6A20) associated with different clinical outcomes [82]. Among them, SLC7A9 is a risk locus for CKD $[83,84]$ and rs12460876, in total LD with rs8101881, had been associated with eGFRcrea [84] . More recently, Rhee et al. identified an association between the minor allele at SLC7A9 locus and lower plasma levels of NG-monomethylarginine, and lower risk of CKD [81].

Metabolites associated with kidney function in the KORA/TwinsUK study were further studied for their association with genome-wide genetic markers. The investigators interrogated pre-existing databases (Multiple Tissue Human Expression Resource (MUTHER) Consortium; Chronic Kidney Disease Genetics (CKDGen) Consortium) and showed a significant association for rs6804368 in GADL1 gene with eGFRcrea after correction for multiple testing $\left(p<6.25 \cdot 10^{-3}\right)[75]$.

\subsection{Diabetic Kidney Disease}

Metabolomic studies in DKD are shown in Table 4.

Acylcarnitines and phospholipids have been the focus of most metabolomics targeted studies in DKD patients [61,85-89]. Serum sphingomyelin (OR: 2.53; $\mathrm{p}=1.5 \cdot 10^{-8}$ ) and HDL particles (OR $\leq 0.40$; $p \leq 3.1 \cdot 10^{-10}$ ) were the strongest predictors for kidney disease adjusted by diabetes duration, age and gender in 326 T1DM patients from the FinnDiane cohort after the established kidney biomarkers (serum creatinine, serum cystatin- $\mathrm{C}$ and serum urea) [61]. Dihydrosphingosine and phytosphingosine showed significant differences in the serum of 41 T2DM Asian patients, compared to 25 controls [90]. Phospholipids within the same class decreased with the development of DKD in plasma of 91 Asian individuals [86]. Urine levels of phospholipids, intermediate-density lipoproteins and LDL, along with 
unsaturated fatty acids were also increased in the early phase of the disease, but not in the late phase of 325 T1DM patients [60]. In the final phase, the sphingolipid pathway was proposed as a mediator of lipotoxicity from saturated fatty acids leading to ESRD and/or premature death $[60,87]$ Several phospholipids were identified as novel biomarkers capable to distinguish T2DM, DKD and healthy individuals in a case control study including 112 diabetic Asian patients [85].

Regarding acylcarnitines, plasma acylcarnitine concentrations were higher in a study comparing 28 uraemic ESRD patients (diabetic and non-diabetic) on chronic haemodialysis with 10 age- and gendermatched healthy controls [89]. The haemodialysis session induced a decline in free, short-chain, medium-chain and dicarboxylic acylcarnitines, whereas the long chain acylcarnitines remained unaffected. A reduction in plasma levels of amino acid proline, ornithine, citrulline and serine was also observed after haemodialysis session [89].

A model including $\gamma$-butyrobetaine (involved in the last step in the L-carnitine biosynthesis pathway), symmetric dimethylarginine (SDMA), and azelaic acid among other unidentified metabolites yielded AUC values of 0.927 ( $\mathrm{Cl}_{95 \%}$ : 0.870-0.983; $\mathrm{p}<0.0001$ ) to discriminate between DKD (32 microalbuminuric DKD and 26 macroalbuminuric DKD) and 20 albuminuric non-DKD patients [91].

Different combinations of plasma levels of fatty acids (esterified and non-esterified) were able to specifically discriminate among every stage of progression, from no disease, to end-stage DKD $(p<0.01)$ in a case control study including 30 controls, 30 T2DM patients without nephropathy and 90 T2DM patients with stages 3-5 CKD [92]. A different distribution of urine unsaturated fatty acids and phospholipids was described in T1DM patients, according to different levels of progression [60].

To determine the contribution of urine metabolomics to the development of CKD in diabetes, 73 T1DM and T2DM patients with diabetes and no kidney disease were compared with 85 patients with diabetes and CKD [93]. After adjustment for potential confounders, including age, gender, diabetes, body mass index, mean arterial pressure, haemoglobin A1c (HbA1c), and duration of diabetes mellitus, 12 metabolites were found associated with the development of CKD [93]. Several of these metabolites proved to be specific for diabetic CKD when this profile was tested in a cohort of 12 patients with biopsy-proven focal segmental glomerulosclerosis (FSGS) who were refractory to standard immunotherapies and had a similar degree of CKD [93].

Adenosine levels gradually increased with the CKD stage in the plasma of 88 Asian DKD patients [94]. There was also a significant increase of levels of adenosine $(p<0.001)$, inosine $(p<0.001)$, xanthine $(p=0.012)$ and uric acid $(p=0.016)$ in DKD patients compared to those with diabetes and no kidney disease [95]. Plasma concentrations of S-adenosylmethionine, S-adenosylhomocysteine showed clear increase in 30 DKD patients, compared to 20 individuals with diabetes and no kidney disease and 30 healthy controls [96]. DKD patients also showed increased plasma concentrations of cysteine, total homocysteine as well as decrease of cysteine-glycine, methionine, and glutathione [96].

Recently, five putative uraemic solutes and essential amino acids have been found associated with progression to ESRD in plasma of 80 T2DM patients, matched for baseline clinical characteristics: $p$ cresol sulphate, phenylacetylglutamine, myo-inositol, pseudouridine, urate [97]. All findings remained statistically significant after adjustment for differences between study groups in albumin excretion rate, eGFR, or HbA1c .

The association of metabolite profiles with eGFR and albuminuria has been investigated in many studies. The search for a serum and/or urine metabolite profile capable of predicting progression of renal failure was recently investigated in a cohort of 286 Italian T2DM patients [98]. Three metabolites (C-glycosyl tryptophan, pseudouridine, and $\mathrm{N}$-acetylthreonine) correlated independently with 
baseline eGFR (adjusted $r^{2}=0.52 ; p<0.0001$ ) and two metabolites (C-glycosyl tryptophan and 1oleoylglycerol) with UACR (adjusted $r^{2}=0.14 ; p<0.0001$ ). An index, calculated as the arithmetic sum of $\mathrm{C}$-glycosyl tryptophan, pseudouridine, and $\mathrm{N}$-acetylthreonine, raised the receiver operator characteristics curve (ROC) calculated with the clinical parameters gender, age, fasting glucose, and baseline eGFR from 0.671 to $0.739(p<0.0001)$ to predict eGFR decline. The same index also predicted a change in UACR with a ROC of 0.821 [98]. Creatinine, aspartic acid, $\nu$-butyrobetaine, citrulline, SDMA, and kynurenine correlated positively with UACR and negatively with eGFR in 78 T2DM Japanese patients [91]. Azelaic and galactaric acids correlated negatively with UACR and positively with eGFR.

A study performed in 325 T1DM patients, including all patients with kidney disease progression (defined as a transition between any stage: normal albumin excretion ratio $\rightarrow$ microalbuminuria $\rightarrow$ macroalbuminuria $\rightarrow$ ESRD), available in the nationwide FinnDiane study, and using clinically similar non-progressors as controls, demonstrated different progression rates in subgroups of patients with metabolically different phenotypes [60]. Patients showing signs of insulin resistance and lipotoxicity from excess saturated fatty acids (phenotype II) had a higher progression rate than patients with a favourable state, with adequate glycaemic control and low overall lipids with similar diabetes duration (phenotype I) (71\% vs 31\%) [60]. Older patients with no lipotoxic and insulin resistant metabolic profile, but showing an increase in $\mathrm{HbA1c}$, cholesterol-rich lipoproteins, phospholipids and unsaturated fatty acids (phenotype III), features shared with phenotype II, had comparable progression rates (66\% vs $71 \%$ ), despite a larger difference in diabetes duration (18 vs 29 years) [60]. Previous investigations in the FinnDiane cohort had identified substituted carnitine, hippuric acid, and S-(3-oxododecanoyl) cysteamine as a urine metabolic profile which discriminated a group of patients with DKD and progression of renal failure from patients with diabetes and normal UAE [62].

Higher signal intensities of octanol, creatinine and $\mathrm{N}$-acetylglutamine and lower signal intensities of oxalic acid, phosphoric acid, benzamide and 3,5-dimethoxymandelic amide were all independent predictors of low eGFR in 90 T2DM Asian patients ( $A \cup C=0.995$ ) [96]. In these patients, a urine panel composed by N6-acetyl-I-lysine, caffeine, 4-methoxyphenylacetic acid, chondroitin sulphate, hyocholic acid/cholic acid/ursocholic acid, phenyl sulphate and $\alpha$-hydroxyhippuric acid was able to predict the development of eGFR $<60 \mathrm{ml} / \mathrm{min} / 1.73 \mathrm{~m}^{2}$ with an AUC of 0.870 , improved up to $A \cup C=0.978$ by the inclusion of age at recruitment and serum creatinine [96].

Plasma butenoylcarnitine correlated positively with changes in UAE, and negatively with changes in eGFR in 80 T2DM patients from the Prevention of REnal and Vascular End-stage Disease (PREVEND) trial ( $p=0.02$ and $p=0.01$, respectively) [88]. In urine, glutamine negatively correlated with changes in UAE and positively correlated with changes in eGFR.

Other metabolites correlated with eGFR (3-hydroxy isovalerate, aconitic acid, glycolic acid, uracil and citric acid) and albuminuria (2-methyl acetoacetate, 3-methyl crotonyl glycine, and 3-methyl adipic acid) have been described in the urine of T1DM and T2DM patients [93].

\subsection{Other Kidney diseases}

Table 5 shows metabolomic studies in patients with primary glomerulonephritis, the most investigated kidney conditions after CKD and DKD. A panel of five urine metabolites (citric acid, pyruvic acid, fructose, ethanolamine, and cysteine) achieved AUCs ranging from 0.889 to 0.951 to discriminate between three primary pathologically confirmed glomerulopathies: minimal change disease (MCD), FSGS and membranous glomerulonephritis (MGN) in 90 Asian patients with primary nephrotic syndrome and 12 controls [99]. Although the results were poorer in the validation set (0.515-0.812), the metabolite combination including methionine, cysteine, citrulline, and pyruvic acid significantly improved the AUC value (0.843) to discriminate between MCD and MGN and had a specificity of $94.4 \%$ 
and sensitivity of $61.1 \%$ [99]. Different urine metabolite patterns were also capable to discriminate between FSGS and control, MGN, IgAN or MCD in a study conducted in 89 primary glomerulopathy patients (FSGS, $n=25 ; M G N, n=24 ; \operatorname{IgAN}, n=26 ; M C D, n=14$ ) and 35 healthy controls [100]. FSGS has also shown different urine metabolite profiles between diabetic and non-diabetic CKD. Sharma et al. used a small cohort of patients $(n=12)$ with biopsy-proven FSGS refractory to standard immunotherapies to determine whether their metabolomic signature was specific for DKD or differed from another type of CKD [93]. Several metabolites demonstrated to be specific for DKD (2-methyl acetoacetate, 3-methyl adipic acid, 3-methyl crotonyl glycine, 3-hydroxy propionate, tiglylglycine), whereas eight overlapped among DKD and FSGS-CKD patients (3-hydroxy isovalerate, aconitic acid, citric acid, 2-ethyl 3-oh propionate, glycolic acid, homovanillic acid, 3-hydroxy isobutyrate and uracil) [93]. MGN patients with high urine protein $(>3.5 \mathrm{~g} / 24 \mathrm{~h}$ ) have shown urine and serum metabolic variations (26 urine and 9 serum metabolites) originated by a more severe injury of kidney function and oxidative stress, compared to those patients with low urine protein concentrations [101]. Impaired filtration function in high urine protein MGN patients, given by the markedly increased serum levels of citric acid and four amino acids, and elevated urine concentration of dicarboxylic acids, phenolic acids, and cholesterol, suggesting more severe oxidative attacks, are among the specific metabolic profiles shown by these patients [101]. In IgAN patients, variable serum concentration of several metabolites, including lactate, myo-inositol, aminoacids, lipids, glucose, glutamate, acetate, 3hydroxybutyrate, and 1-methylhistidine among others have also been proposed as candidate biomarkers for the risk of developing this disease [102].

The variability of urinary and plasma metabolomes has also been investigated to identify metabolic signatures in other kidney-related diseases, such as CKD-mineral and bone disorder (CKD-MBD), ADPKD and acute transplant injury (ATI), as shown in Table 6.

Serum metabolic profile has shown the potential to be used as a diagnostic tool for differentiating SLE from healthy controls as well as from other similar immunological diseases such as systemic sclerosis and primary Sjögrens syndrome in a recent small study in Caucasians [103]. In particular, SLE patients showed prevalent oxidative and altered tryptophan metabolism either through changes in the activity of the aromatic amino acid decarboxylase or the kynurenine pathway [103]. Differences in urinary metabolites between proliferative LN and membranous LN patients, and between LN and FSGS patients were also shown in a small study with mixed population [104]. Class V LN showed lower citrate and higher taurine urinary levels compared to class III/IV LN patients. The lack of hippurate in urine was characteristic of FSGS patients [104].

Individuals with secondary hyperparathyroidism (intact parathyroid hormone (PTH) 150-300 pg/ml) had lower serum concentrations of cytidine and L-phenylalanine compared to controls in a study including 76 uraemic Asian patients receiving maintenance peritoneal dialysis [105]. Different metabolic patterns were shown in the high-PTH group as compared with the low-PTH group. Among other changes, the increased level of hydroxyproline in high-PTH patients suggested this metabolite may be a potential marker for the onset of CKD-MBD [105].

The levels of ADMA as a marker of an inhibitor of nitric oxide synthase and the lipid peroxidation product 13-hydroxyoctadecadienoic acid as a marker of oxidative stress was investigated in 27 patients with early ADPKD and 30 age-matched volunteers [106]. Plasma levels of both metabolites were increased in patients with early ADPKD, along with decreased ADMA urinary clearance, suggesting this process is accompanied by oxidative stress [106].

Urine metabolomics has also been used to monitor renal allograft function in five Asian transplant recipients whose biopsy specimens showed slight or moderate ATI or acute tubular necrosis (ATN) 
[107]. Changes among urine small molecule metabolites were capable to distinguish between ATI and ATN status after transplantation [107].

\subsection{Conclusions}

Data from metabolomics GWAS demonstrate that there are differences in individual metabolic profiles in blood and / or urine that may be linked to underlying genetic variation but we are still not at a point where an integrated "metabologenomic" profile can be provided for a person with kidney disease.

Most of the studies of metabolomics in CKD are limited by small sample sizes and by the potential differences among the populations evaluated. Many metabolomic profiles have been described, with multiple metabolites involved and several different panels proposed with variable accuracy. Despite this, some metabolites such as TMAO, kynurenine and citrulline stand out as potential biomarkers in CKD.

Many different metabolomics profiles have been described in diabetic patients but only a few metabolites have been found in common between studies. Acylcarnitines and phospholipids are the most frequently described potential biomarkers, but probably because of the targeted nature of most of the studies.

The relevance of different metabolomics profiles in primary glomerulonephritis has been less well investigated and most studies are underpowered in size making it difficult to evaluate fully proposed metabolic candidates.

\section{Concluding Remarks}

Proteomic and metabolomic studies have tried to fill the gap created by the critical limitations of the current clinical biomarkers (serum creatinine and urinary albumin) used to diagnose and stratify CKD. This gap is especially evident in certain scenarios, such as the early stages of CKD and diagnosis of CKD in elderly individuals or those with extreme body mass index values where the current clinical biomarkers have limited sensitivity and specificity.

The proteomic CKD273 classifier is a biomarker panel with the potential to be used in clinical practice. However, all the studies for the development and evaluation of this urinary peptides-based classifier have been undertaken by the same research group, led by Harold Mischak, who founded the company commercialising the biomarker panel and is also involved in the interventional trial. Therefore, the data on the CKD273 panel, although derived from many well conducted studies, including multicentre and longitudinal cohorts, does need further replication by independent researchers (as advocated by the FDA).

The role of metabolomic biomarkers in renal diseases remains unclear. Despite the numerous studies attempting to identify reliable metabolomic biomarkers many are small in scale and undertaken in different populations with various technologies. Studies in larger populations, sampled adequately to determine the incidence and prevalence of the specific kidney disease, are needed to fully evaluate how novel metabolomic biomarkers perform as clinical tests in the different subgroups of patients. The distribution of the patients in the sample used to develop the biomarker should resemble the actual proportions in the population of interest, for the generalisation of the biomarker to be possible. Relatively few metabolomic biomarkers associated with CKD have had significant replication of the association in alternative studies thereby limiting the immediate clinical translation of these findings. Inadequate statistical analyses are compounding this lack of replication. The appropriate statistical 
methodologies should be applied, including multiple testing adjustment when necessary, to ensure the conclusions are reflecting true associations.

Routine clinical use of proteomic and metabolomic biomarkers will require agreed protocols for the collection and processing of samples as well as standardisation of the analysis methods. The biomarkers proposed as potential diagnostic tools should be tested against the current assays of urinary albumin, serum creatinine and serum cystatin $C$ used in the clinical practice to evaluate whether the novel proteomic and metabolomic biomarkers do provide improved diagnostic accuracy at acceptable cost.

\section{Acknowledgments}

MCG and KA are funded by a Science Foundation Ireland-Department for the Economy (SFI-DFE) Investigator Program Partnership Award (15/IA/3152).

\section{Author Contributions}

Amy Jayne McKnight: Conceptualization, Formal Analysis, Funding Acquisition, Methodology, Project Administration, Resources, Supervision, Writing (Original Draft Preparation), Writing (Review \& Editing).

Marisa Cañadas-Garre: Conceptualization, Data Curation, Formal Analysis, Investigation, Methodology, Project Administration, Software, Supervision, Visualization, Writing (Original Draft Preparation), Writing (Review \& Editing).

Kerry Anderson: Conceptualization, Data Curation, Formal Analysis, Investigation, Methodology, Visualization, Writing (Original Draft Preparation), Writing (Review \& Editing).

Jayne McGoldrick: Conceptualization, Data Curation, Formal Analysis, Investigation, Methodology, Visualization, Writing (Original Draft Preparation).

Alexander Peter Maxwell: Conceptualization, Formal Analysis, Funding Acquisition, Methodology, Project Administration, Resources, Supervision, Writing (Original Draft Preparation), Writing (Review \& Editing).

\section{Table Legends}

Table 1. Proteomic studies in chronic kidney disease

Table 2. Advantages and disadvantages of the two most common technologies used in metabolomics

Table 3. Metabolomics studies in chronic kidney disease

Table 4. Metabolomics studies in diabetic kidney disease

Table 5. Metabolomics studies in primary glomerulonephritis

Table 6. Metabolomics studies in other kidney diseases

\section{Figure Legends}

Figure 1. Chronic kidney disease progression, classification according to estimated glomerular filtration rate and albuminuria, main therapeutic approaches and current available biomarkers. The changing shades of the kidneys indicate decrease in renal function and the shades in the rectangles, increasing intensity of surveillance and therapy for chronic kidney disease. The stars show transition 
stages where new molecular biomarkers may add a benefit in the clinical management of CKD. (Abbreviations: ACEi: angiotensin converting enzyme inhibitor; ACR: albumin-to-creatinine ratio (mg/g); AKI: acute kidney injury; ARB: angiotensin II receptor blockers; CKD: chronic kidney disease; DM: diabetes mellitus; eGFR: estimated glomerular filtration rate $(\mathrm{ml} / \mathrm{min} / 1.73 \mathrm{~m} 2)$; GFR: glomerular filtration rate; HbA1c: haemoglobin A1c; NSAIDs: nonsteroidal anti-inflammatory drugs; RAAS: reninangiotensin-aldosterone system).

Figure 2. Main molecular entities identified by proteomic or metabolomic analysis as potential biomarkers in chronic kidney disease (Abbreviations: CKD: chronic kidney disease; ECM: extracellular matrix).

\section{References}

[1] The Kidney Disease Outcomes Quality Initiative (KDOQI), KDIGO 2012 Clinical Practice Guideline for the Evaluation and Management of Chronic Kidney Disease, Off. J. Int. Soc. Nephrol. 3 (2013).

[2] K. Bruck, V.S. Stel, G. Gambaro, S. Hallan, H. Volzke, J. Arnlov, M. Kastarinen, I. Guessous, J. Vinhas, B. Stengel, H. Brenner, J. Chudek, S. Romundstad, C. Tomson, A.O. Gonzalez, A.K. Bello, J. Ferrieres, L. Palmieri, G. Browne, V. Capuano, W. Van Biesen, C. Zoccali, R. Gansevoort, G. Navis, D. Rothenbacher, P.M. Ferraro, D. Nitsch, C. Wanner, K.J. Jager, CKD Prevalence Varies across the European General Population., J. Am. Soc. Nephrol. 27 (2016) 2135-2147. doi:10.1681/ASN.2015050542.

[3] R.M. Tanner, O.M. Gutierrez, S. Judd, W. McClellan, C.B. Bowling, B.D. Bradbury, M.M. Safford, M. Cushman, D. Warnock, P. Muntner, Geographic variation in CKD prevalence and ESRD incidence in the United States: results from the reasons for geographic and racial differences in stroke (REGARDS) study., Am. J. Kidney Dis. 61 (2013) 395-403. doi:10.1053/j.ajkd.2012.10.018.

[4] Global Facts: About Kidney Disease | National Kidney Foundation, (n.d.). https://www.kidney.org/kidneydisease/global-facts-about-kidney-disease (accessed July 6, 2018).

[5] M. Yashiro, T. Kamata, H. Segawa, Y. Kadoya, T. Murakami, E. Muso, Comparisons of cystatin C with creatinine for evaluation of renal function in chronic kidney disease, Clin. Exp. Nephrol. 13 (2009) 598-604. doi:10.1007/s10157-009-0202-6.

[6] M. Rasuk, G. Ferrer, J. Moreno, M. Farias, V. Albarracín, The diversity of microbial extremophiles, in: T.B. Rdrigues, A.E. Trindade Silva (Eds.), Mol. Divers. Environ. Prokaryotes, CRC Press. Taylor \& Francis Group, 2016: pp. 87-126.

[7] L. Molin, R. Seraglia, A. Lapolla, E. Ragazzi, J. Gonzalez, A. Vlahou, J.P. Schanstra, A. Albalat, M. Dakna, J. Siwy, J. Jankowski, V. Bitsika, H. Mischak, P. Zürbig, P. Traldi, A comparison between MALDI-MS and CE-MS data for biomarker assessment in chronic kidney diseases, J. Proteomics. 75 (2012) 5888-5897. doi:10.1016/j.jprot.2012.07.024.

[8] M. Frantzi, A. Latosinska, L. Flühe, M.C. Hupe, E. Critselis, M.W. Kramer, A.S. Merseburger, H. Mischak, A. Vlahou, Developing proteomic biomarkers for bladder cancer: towards clinical application., Nat. Rev. Urol. 12 (2015) 317-30. doi:10.1038/nrurol.2015.100.

[9] V. Thongboonkerd, Recent progress in urinary proteomics., Proteomics. Clin. Appl. 1 (2007) 780-91. doi:10.1002/prca.200700035.

[10] J. Klein, J.-L. Bascands, H. Mischak, J.P. Schanstra, The role of urinary peptidomics in kidney 
disease research., Kidney Int. 89 (2016) 539-45. doi:10.1016/j.kint.2015.10.010.

[11] D.M. Good, P. Zürbig, A. Argilés, H.W. Bauer, G. Behrens, J.J. Coon, M. Dakna, S. Decramer, C. Delles, A.F. Dominiczak, J.H.H. Ehrich, F. Eitner, D. Fliser, M. Frommberger, A. Ganser, M.A. Girolami, I. Golovko, W. Gwinner, M. Haubitz, S. Herget-Rosenthal, J. Jankowski, H. Jahn, G. Jerums, B.A. Julian, M. Kellmann, V. Kliem, W. Kolch, A.S. Krolewski, M. Luppi, Z. Massy, M. Melter, C. Neusüss, J. Novak, K. Peter, K. Rossing, H. Rupprecht, J.P. Schanstra, E. Schiffer, J.-U. Stolzenburg, L. Tarnow, D. Theodorescu, V. Thongboonkerd, R. Vanholder, E.M. Weissinger, H. Mischak, P. Schmitt-Kopplin, Naturally occurring human urinary peptides for use in diagnosis of chronic kidney disease., Mol. Cell. Proteomics. 9 (2010) 2424-37. doi:10.1074/mcp.M110.001917.

[12] J. Siwy, J.P. Schanstra, A. Argiles, S.J.L. Bakker, J. Beige, P. Boucek, K. Brand, C. Delles, F. Duranton, B. Fernandez-Fernandez, M.-L. Jankowski, M. Al Khatib, T. Kunt, M. Lajer, R. Lichtinghagen, M. Lindhardt, D.M. Maahs, H. Mischak, W. Mullen, G. Navis, M. Noutsou, A. Ortiz, F. Persson, J.R. Petrie, J.M. Roob, P. Rossing, P. Ruggenenti, I. Rychlik, A.L. Serra, J. SnellBergeon, G. Spasovski, O. Stojceva-Taneva, M. Trillini, H. von der Leyen, B.M. Winklhofer-Roob, P. Zürbig, J. Jankowski, Multicentre prospective validation of a urinary peptidome-based classifier for the diagnosis of type 2 diabetic nephropathy., Nephrol. Dial. Transplant. 29 (2014) 1563-70. doi:10.1093/ndt/gfu039.

[13] S. Andersen, H. Mischak, P. Zürbig, H.-H. Parving, P. Rossing, Urinary proteome analysis enables assessment of renoprotective treatment in type 2 diabetic patients with microalbuminuria., BMC Nephrol. 11 (2010) 29. doi:10.1186/1471-2369-11-29.

[14] P. Zürbig, G. Jerums, P. Hovind, R.J. Macisaac, H. Mischak, S.E. Nielsen, S. Panagiotopoulos, F. Persson, P. Rossing, Urinary proteomics for early diagnosis in diabetic nephropathy., Diabetes. 61 (2012) 3304-13. doi:10.2337/db12-0348.

[15] Á. Argilés, J. Siwy, F. Duranton, N. Gayrard, M. Dakna, U. Lundin, L. Osaba, C. Delles, G. Mourad, K.M. Weinberger, H. Mischak, CKD273, a new proteomics classifier assessing CKD and its prognosis., PLoS One. 8 (2013) e62837. doi:10.1371/journal.pone.0062837.

[16] Y.-M. Gu, L. Thijs, Y.-P. Liu, Z. Zhang, L. Jacobs, T. Koeck, P. Zürbig, R. Lichtinghagen, K. Brand, T. Kuznetsova, L. Olivi, P. Verhamme, C. Delles, H. Mischak, J.A. Staessen, The urinary proteome as correlate and predictor of renal function in a population study., Nephrol. Dial. Transplant. 29 (2014) 2260-8. doi:10.1093/ndt/gfu234.

[17] J.P. Schanstra, P. Zürbig, A. Alkhalaf, A. Argiles, S.J.L. Bakker, J. Beige, H.J.G. Bilo, C. Chatzikyrkou, M. Dakna, J. Dawson, C. Delles, H. Haller, M. Haubitz, H. Husi, J. Jankowski, G. Jerums, N. Kleefstra, T. Kuznetsova, D.M. Maahs, J. Menne, W. Mullen, A. Ortiz, F. Persson, P. Rossing, P. Ruggenenti, I. Rychlik, A.L. Serra, J. Siwy, J. Snell-Bergeon, G. Spasovski, J.A. Staessen, A. Vlahou, H. Mischak, R. Vanholder, Diagnosis and Prediction of CKD Progression by Assessment of Urinary Peptides., J. Am. Soc. Nephrol. 26 (2015) 1999-2010. doi:10.1681/ASN.2014050423.

[18] M. Lindhardt, F. Persson, G. Currie, C. Pontillo, J. Beige, C. Delles, H. von der Leyen, H. Mischak, G. Navis, M. Noutsou, A. Ortiz, P.L. Ruggenenti, I. Rychlik, G. Spasovski, P. Rossing, Proteomic prediction and Renin angiotensin aldosterone system Inhibition prevention Of early diabetic nephRopathy in TYpe 2 diabetic patients with normoalbuminuria (PRIORITY): essential study design and rationale of a randomised clinical multicentre trial, BMJ Open. 6 (2016) e010310. doi:10.1136/bmjopen-2015-010310.

[19] S.S. Roscioni, D. de Zeeuw, M.E. Hellemons, H. Mischak, P. Zürbig, S.J.L. Bakker, R.T. Gansevoort, H. Reinhard, F. Persson, M. Lajer, P. Rossing, H.J.L. Heerspink, A urinary peptide 
biomarker set predicts worsening of albuminuria in type 2 diabetes mellitus, Diabetologia. 56 (2013) 259-267. doi:10.1007/s00125-012-2755-2.

[20] C. Pontillo, L. Jacobs, J.A. Staessen, J.P. Schanstra, P. Rossing, H.J.L. Heerspink, J. Siwy, W. Mullen, A. Vlahou, H. Mischak, R. Vanholder, P. Zürbig, J. Jankowski, A urinary proteome-based classifier for the early detection of decline in glomerular filtration., Nephrol. Dial. Transplant. 32 (2017) 1510-1516. doi:10.1093/ndt/gfw239.

[21] C. Pontillo, Z.-Y. Zhang, J.P. Schanstra, L. Jacobs, P. Zürbig, L. Thijs, A. Ramírez-Torres, H.J.L. Heerspink, M. Lindhardt, R. Klein, T. Orchard, M. Porta, R.W. Bilous, N. Charturvedi, P. Rossing, A. Vlahou, E. Schepers, G. Glorieux, W. Mullen, C. Delles, P. Verhamme, R. Vanholder, J.A. Staessen, H. Mischak, J. Jankowski, Prediction of Chronic Kidney Disease Stage 3 by CKD273, a Urinary Proteomic Biomarker., Kidney Int. Reports. 2 (2017) 1066-1075. doi:10.1016/j.ekir.2017.06.004.

[22] F. Genovese, A.A. Manresa, D.J. Leeming, M.A. Karsdal, P. Boor, The extracellular matrix in the kidney: a source of novel non-invasive biomarkers of kidney fibrosis?, Fibrogenesis Tissue Repair. 7 (2014) 4. doi:10.1186/1755-1536-7-4.

[23] M.A. Øvrehus, P. Zürbig, B.E. Vikse, S.I. Hallan, Urinary proteomics in chronic kidney disease: diagnosis and risk of progression beyond albuminuria., Clin. Proteomics. 12 (2015) 21. doi:10.1186/s12014-015-9092-7.

[24] C. Pontillo, H. Mischak, Urinary peptide-based classifier CKD273: towards clinical application in chronic kidney disease., Clin. Kidney J. 10 (2017) 192-201. doi:10.1093/ckj/sfx002.

[25] M. Lindhardt, F. Persson, C. Oxlund, I.A. Jacobsen, P. Zürbig, H. Mischak, P. Rossing, H.J.L. Heerspink, Predicting albuminuria response to spironolactone treatment with urinary proteomics in patients with type 2 diabetes and hypertension, Nephrol. Dial. Transplant. (2017) gfw406. doi:10.1093/ndt/gfw406.

[26] Food and Drug Administration, Center for Drug Evaluation and Research, Letter of Support to Mosaiques Diagnostics GrnbH to encourage the further development of KD273, 2016.

[27] E. Critselis, A. Vlahou, V.S. Stel, R.L. Morton, Cost-effectiveness of screening type 2 diabetes patients for chronic kidney disease progression with the CKD273 urinary peptide classifier as compared to urinary albumin excretion., Nephrol. Dial. Transplant. (2017). doi:10.1093/ndt/gfx068.

[28] G.E. Currie, B.J. von Scholten, S. Mary, J.-L. Flores Guerrero, M. Lindhardt, H. Reinhard, P.K. Jacobsen, W. Mullen, H.-H. Parving, H. Mischak, P. Rossing, C. Delles, Urinary proteomics for prediction of mortality in patients with type 2 diabetes and microalbuminuria., Cardiovasc. Diabetol. 17 (2018) 50. doi:10.1186/s12933-018-0697-9.

[29] E. Nkuipou-Kenfack, F. Duranton, N. Gayrard, A. Argiles, U. Lundin, K.M. Weinberger, M. Dakna, C. Delles, W. Mullen, H. Husi, J. Klein, T. Koeck, P. Zurbig, H. Mischak, Assessment of metabolomic and proteomic biomarkers in detection and prognosis of progression of renal function in chronic kidney disease., PLoS One. 9 (2014) e96955. doi:10.1371/journal.pone.0096955.

[30] E. Nkuipou-Kenfack, F. Duranton, N. Gayrard, À. Argilés, U. Lundin, K.M. Weinberger, M. Dakna, C. Delles, W. Mullen, H. Husi, J. Klein, T. Koeck, P. Zürbig, H. Mischak, Assessment of Metabolomic and Proteomic Biomarkers in Detection and Prognosis of Progression of Renal Function in Chronic Kidney Disease, PLoS One. 9 (2014) e96955. doi:10.1371/journal.pone.0096955. 
[31] V.O. Shah, R.R. Townsend, H.I. Feldman, K.L. Pappan, E. Kensicki, D.L. Vander Jagt, Plasma metabolomic profiles in different stages of CKD., Clin. J. Am. Soc. Nephrol. 8 (2013) 363-370. doi:10.2215/CJN.05540512.

[32] K. Markoska, M. Pejchinovski, C. Pontillo, P. Zürbig, L. Jacobs, A. Smith, J. Masin-Spasovska, O. Stojceva-Taneva, M. Polenakovic, F. Magni, H. Mischak, G. Spasovski, Urinary peptide biomarker panel associated with an improvement in estimated glomerular filtration rate in chronic kidney disease patients., Nephrol. Dial. Transplant. (2017). doi:10.1093/ndt/gfx263.

[33] Z.-Y. Zhang, S. Ravassa, M. Pejchinovski, W.-Y. Yang, P. Zurbig, B. Lopez, F.-F. Wei, L. Thijs, L. Jacobs, A. Gonzalez, J.-U. Voigt, P. Verhamme, T. Kuznetsova, J. Diez, H. Mischak, J.A. Staessen, A Urinary Fragment of Mucin-1 Subunit alpha Is a Novel Biomarker Associated With Renal Dysfunction in the General Population., Kidney Int. Reports. 2 (2017) 811-820. doi:10.1016/j.ekir.2017.03.012.

[34] K.B. Rubinow, C.M. Henderson, C. Robinson-Cohen, J. Himmelfarb, I.H. de Boer, T. Vaisar, B. Kestenbaum, A.N. Hoofnagle, Kidney function is associated with an altered protein composition of high-density lipoprotein., Kidney Int. 92 (2017) 1526-1535. doi:10.1016/j.kint.2017.05.020.

[35] U. Naseeb, J. Shafqat, T. Jagerbrink, S. Zarina, A. Alvestrand, H. Jornvall, J. Axelsson, Proteome patterns in uremic plasma., Blood Purif. 26 (2008) 561-568. doi:10.1159/000178773.

[36] G. Remuzzi, M. Macia, P. Ruggenenti, Prevention and Treatment of Diabetic Renal Disease in Type 2 Diabetes: The BENEDICT Study, J. Am. Soc. Nephrol. 17 (2006) S90-S97. doi:10.1681/ASN.2005121324.

[37] A. Lapolla, R. Seraglia, L. Molin, K. Williams, C. Cosma, R. Reitano, A. Sechi, E. Ragazzi, P. Traldi, Low molecular weight proteins in urines from healthy subjects as well as diabetic, nephropathic and diabetic-nephropathic patients: a MALDI study., J. Mass Spectrom. 44 (2009) 419-25. doi:10.1002/jms.1520.

[38] A. Alkhalaf, P. Zürbig, S.J.L. Bakker, H.J.G. Bilo, M. Cerna, C. Fischer, S. Fuchs, B. Janssen, K. Medek, H. Mischak, J.M. Roob, K. Rossing, P. Rossing, I. Rychlík, H. Sourij, B. Tiran, B.M. Winklhofer-Roob, G.J. Navis, for the P. PREDICTIONS Group, Multicentric validation of proteomic biomarkers in urine specific for diabetic nephropathy., PLoS One. 5 (2010) e13421. doi:10.1371/journal.pone.0013421.

[39] K. Rossing, H. Mischak, M. Dakna, P. Zürbig, J. Novak, B.A. Julian, D.M. Good, J.J. Coon, L. Tarnow, P. Rossing, PREDICTIONS Network, Urinary proteomics in diabetes and CKD., J. Am. Soc. Nephrol. 19 (2008) 1283-90. doi:10.1681/ASN.2007091025.

[40] N.M. Bhensdadia, K.J. Hunt, M.F. Lopes-Virella, J. Michael Tucker, M.R. Mataria, J.L. Alge, B.A. Neely, M.G. Janech, J.M. Arthur, for the members of the V.A.D.T. (VADT) study Veterans Affairs Diabetes Trial (VADT) study group, Urine haptoglobin levels predict early renal functional decline in patients with type 2 diabetes., Kidney Int. 83 (2013) 1136-43. doi:10.1038/ki.2013.57.

[41] K. Sharma, S. Lee, S. Han, S. Lee, B. Francos, P. McCue, R. Wassell, M.A. Shaw, S.P. RamachandraRao, Two-dimensional fluorescence difference gel electrophoresis analysis of the urine proteome in human diabetic nephropathy., Proteomics. 5 (2005) 2648-55. doi:10.1002/pmic.200401288.

[42] J. Jin, Y.H. Ku, Y. Kim, Y. Kim, K. Kim, J.Y. Lee, Y.M. Cho, H.K. Lee, K.S. Park, Y. Kim, Differential proteome profiling using ITRAQ in microalbuminuric and normoalbuminuric type 2 diabetic patients., Exp. Diabetes Res. 2012 (2012) 168602. doi:10.1155/2012/168602. 
[43] M. Papale, S. Di Paolo, R. Magistroni, O. Lamacchia, A.M. Di Palma, A. De Mattia, M.T. Rocchetti, L. Furci, S. Pasquali, S. De Cosmo, M. Cignarelli, L. Gesualdo, Urine proteome analysis may allow noninvasive differential diagnosis of diabetic nephropathy., Diabetes Care. 33 (2010) 24092415. doi:10.2337/dc10-0345.

[44] H. Dihazi, G.A. Müller, S. Lindner, M. Meyer, A.R. Asif, M. Oellerich, F. Strutz, Characterization of diabetic nephropathy by urinary proteomic analysis: identification of a processed ubiquitin form as a differentially excreted protein in diabetic nephropathy patients., Clin. Chem. 53 (2007) 1636-45. doi:10.1373/clinchem.2007.088260.

[45] E. Bellei, E. Rossi, L. Lucchi, S. Uggeri, A. Albertazzi, A. Tomasi, A. lannone, Proteomic analysis of early urinary biomarkers of renal changes in type 2 diabetic patients., Proteomics. Clin. Appl. 2 (2008) 478-91. doi:10.1002/prca.200780109.

[46] S. Jain, A. Rajput, Y. Kumar, N. Uppuluri, A.S. Arvind, U. Tatu, Proteomic analysis of urinary protein markers for accurate prediction of diabetic kidney disorder., J. Assoc. Physicians India. 53 (2005) 513-20.

[47] W. Gu, L.-X. Zou, P.-F. Shan, Y.-D. Chen, Analysis of urinary proteomic patterns for diabetic nephropathy by ProteinChip., Proteomics. Clin. Appl. 2 (2008) 744-50. doi:10.1002/prca.200780083.

[48] H. Jiang, G. Guan, R. Zhang, G. Liu, J. Cheng, X. Hou, Y. Cui, Identification of urinary soluble Ecadherin as a novel biomarker for diabetic nephropathy., Diabetes. Metab. Res. Rev. 25 (2009) 232-41. doi:10.1002/dmrr.940.

[49] P. V Rao, X. Lu, M. Standley, P. Pattee, G. Neelima, G. Girisesh, K. V Dakshinamurthy, C.T. Roberts, S.R. Nagalla, Proteomic identification of urinary biomarkers of diabetic nephropathy., Diabetes Care. 30 (2007) 629-37. doi:10.2337/dc06-2056.

[50] A. Caseiro, R. Ferreira, C. Quintaneiro, A. Pereira, R. Marinheiro, R. Vitorino, F. Amado, Protease profiling of different biofluids in type 1 diabetes mellitus., Clin. Biochem. 45 (2012) 1613-9. doi:10.1016/j.clinbiochem.2012.08.027.

[51] M.L. Merchant, B.A. Perkins, G.M. Boratyn, L.H. Ficociello, D.W. Wilkey, M.T. Barati, C.C. Bertram, G.P. Page, B.H. Rovin, J.H. Warram, A.S. Krolewski, J.B. Klein, Urinary peptidome may predict renal function decline in type 1 diabetes and microalbuminuria., J. Am. Soc. Nephrol. 20 (2009) 2065-74. doi:10.1681/ASN.2008121233.

[52] K.M. Thrailkill, T. Nimmo, R.C. Bunn, G.E. Cockrell, C.S. Moreau, S. Mackintosh, R.D. Edmondson, J.L. Fowlkes, Microalbuminuria in type 1 diabetes is associated with enhanced excretion of the endocytic multiligand receptors megalin and cubilin., Diabetes Care. 32 (2009) 1266-8. doi:10.2337/dc09-0112.

[53] A. Konvalinka, I. Batruch, T. Tokar, A. Dimitromanolakis, S. Reid, X. Song, Y. Pei, A.P. Drabovich, E.P. Diamandis, I. Jurisica, J.W. Scholey, Quantification of angiotensin II-regulated proteins in urine of patients with polycystic and other chronic kidney diseases by selected reaction monitoring., Clin. Proteomics. 13 (2016) 16. doi:10.1186/s12014-016-9117-x.

[54] A. Aggarwal, R. Gupta, V.S. Negi, L. Rajasekhar, R. Misra, P. Singh, V. Chaturvedi, S. Sinha, Urinary haptoglobin, alpha-1 anti-chymotrypsin and retinol binding protein identified by proteomics as potential biomarkers for lupus nephritis, Clin. Exp. Immunol. 188 (2017) 254262. doi:10.1111/cei.12930.

[55] J.K. Nicholson, J.C. Lindon, E. Holmes, "Metabonomics": understanding the metabolic responses of living systems to pathophysiological stimuli via multivariate statistical analysis of 
biological NMR spectroscopic data, Xenobiotica. $29 \quad$ (1999) 1181-1189. doi:10.1080/004982599238047.

[56] R.H. Weiss, K. Kim, Metabolomics in the study of kidney diseases, Nat. Rev. Nephrol. 8 (2011) 22-33. doi:10.1038/nrneph.2011.152.

[57] G. Thanassoulis, C.Y. Campbell, D.S. Owens, J.G. Smith, A. V. Smith, G.M. Peloso, K.F. Kerr, S. Pechlivanis, M.J. Budoff, T.B. Harris, R. Malhotra, K.D. O'Brien, P.R. Kamstrup, B.G. Nordestgaard, A. Tybjaerg-Hansen, M.A. Allison, T. Aspelund, M.H. Criqui, S.R. Heckbert, S.-J. Hwang, Y. Liu, M. Sjogren, J. van der Pals, H. Kälsch, T.W. Mühleisen, M.M. Nöthen, L.A. Cupples, M. Caslake, E. Di Angelantonio, J. Danesh, J.I. Rotter, S. Sigurdsson, Q. Wong, R. Erbel, S. Kathiresan, O. Melander, V. Gudnason, C.J. O'Donnell, W.S. Post, CHARGE Extracoronary Calcium Working Group, Genetic Associations with Valvular Calcification and Aortic Stenosis, N. Engl. J. Med. 368 (2013) 503-512. doi:10.1056/NEJMoa1109034.

[58] R. Holle, M. Happich, H. Löwel, H. Wichmann, for the M.S. Group, KORA - A Research Platform for Population Based Health Research, Das Gesundheitswes. 67 (2005) 19-25. doi:10.1055/s2005-858235.

[59] K. Suhre, S.-Y. Shin, A.-K. Petersen, R.P. Mohney, D. Meredith, B. Wägele, E. Altmaier, CARDIoGRAM, P. Deloukas, J. Erdmann, E. Grundberg, C.J. Hammond, M.H. de Angelis, G. Kastenmüller, A. Köttgen, F. Kronenberg, M. Mangino, C. Meisinger, T. Meitinger, H.-W. Mewes, M. V Milburn, C. Prehn, J. Raffler, J.S. Ried, W. Römisch-Margl, N.J. Samani, K.S. Small, H.-E. Wichmann, G. Zhai, T. Illig, T.D. Spector, J. Adamski, N. Soranzo, C. Gieger, Human metabolic individuality in biomedical and pharmaceutical research., Nature. 477 (2011) 54-60. doi:10.1038/nature10354.

[60] V.-P. Mäkinen, T. Tynkkynen, P. Soininen, T. Peltola, A.J. Kangas, C. Forsblom, L.M. Thorn, K. Kaski, R. Laatikainen, M. Ala-Korpela, P.-H. Groop, Metabolic diversity of progressive kidney disease in 325 patients with type 1 diabetes (the FinnDiane Study)., J. Proteome Res. 11 (2012) 1782-90. doi:10.1021/pr201036j.

[61] V.-P. Mäkinen, T. Tynkkynen, P. Soininen, C. Forsblom, T. Peltola, A.J. Kangas, P.-H. Groop, M. Ala-Korpela, Sphingomyelin is associated with kidney disease in type 1 diabetes (The FinnDiane Study), Metabolomics. 8 (2012) 369-375. doi:10.1007/s11306-011-0343-y.

[62] F.M. van der Kloet, F.W.A. Tempels, N. Ismail, R. van der Heijden, P.T. Kasper, M. Rojas-Cherto, R. van Doorn, G. Spijksma, M. Koek, J. van der Greef, V.P. Mäkinen, C. Forsblom, H. Holthöfer, P.H. Groop, T.H. Reijmers, T. Hankemeier, Discovery of early-stage biomarkers for diabetic kidney disease using ms-based metabolomics (FinnDiane study)., Metabolomics. 8 (2012) 109119. doi:10.1007/s11306-011-0291-6.

[63] H. Völzke, Study of Health in Pomerania (SHIP), Bundesgesundheitsblatt - Gesundheitsforsch. Gesundheitsschutz. 55 (2012) 790-794. doi:10.1007/s00103-012-1483-6.

[64] E.P. Rhee, C.B. Clish, A. Ghorbani, M.G. Larson, S. Elmariah, E. McCabe, Q. Yang, S. Cheng, K. Pierce, A. Deik, A.L. Souza, L. Farrell, C. Domos, R.W. Yeh, I. Palacios, K. Rosenfield, R.S. Vasan, J.C. Florez, T.J. Wang, C.S. Fox, R.E. Gerszten, A combined epidemiologic and metabolomic approach improves CKD prediction., J. Am. Soc. Nephrol. 24 (2013) 1330-8. doi:10.1681/ASN.2012101006.

[65] F. Duranton, U. Lundin, N. Gayrard, H. Mischak, M. Aparicio, G. Mourad, J.-P. Daures, K.M. Weinberger, A. Argiles, Plasma and Urinary Amino Acid Metabolomic Profiling in Patients with Different Levels of Kidney Function, Clin. J. Am. Soc. Nephrol. 9 (2014) 37-45. doi:10.2215/CJN.06000613. 
[66] J.C. Schefold, J.-P. Zeden, C. Fotopoulou, S. von Haehling, R. Pschowski, D. Hasper, H.-D. Volk, C. Schuett, P. Reinke, Increased indoleamine 2,3-dioxygenase (IDO) activity and elevated serum levels of tryptophan catabolites in patients with chronic kidney disease: a possible link between chronic inflammation and uraemic symptoms, Nephrol. Dial. Transplant. 24 (2009) 1901-1908. doi:10.1093/ndt/gfn739.

[67] T. Kobayashi, T. Yoshida, T. Fujisawa, Y. Matsumura, T. Ozawa, H. Yanai, A. Iwasawa, T. Kamachi, K. Fujiwara, M. Kohno, N. Tanaka, A metabolomics-based approach for predicting stages of chronic kidney disease, Biochem. Biophys. Res. Commun. 445 (2014) 412-416. doi:10.1016/j.bbrc.2014.02.021.

[68] O.-N. Goek, C. Prehn, P. Sekula, W. Romisch-Margl, A. Doring, C. Gieger, M. Heier, W. Koenig, R. Wang-Sattler, T. Illig, K. Suhre, J. Adamski, A. Kottgen, C. Meisinger, Metabolites associate with kidney function decline and incident * chronic kidney disease in the general population, Nephrol. Dial. Transplant. 28 (2013) 2131-2138. doi:10.1093/ndt/gft217.

[69] J. Lee, J.-Y. Choi, Y.-K. Kwon, D. Lee, H.-Y. Jung, H.-M. Ryu, J.-H. Cho, D.H. Ryu, Y.-L. Kim, G.-S. Hwang, Changes in serum metabolites with the stage of chronic kidney disease: Comparison of diabetes and non-diabetes, Clin. Chim. Acta. 459 (2016) 123-131. doi:10.1016/j.cca.2016.05.018.

[70] M. Posada-Ayala, I. Zubiri, M. Martin-Lorenzo, A. Sanz-Maroto, D. Molero, L. Gonzalez-Calero, B. Fernandez-Fernandez, F. de la Cuesta, C.M. Laborde, M.G. Barderas, A. Ortiz, F. Vivanco, G. Alvarez-Llamas, Identification of a urine metabolomic signature in patients with advancedstage chronic kidney disease., Kidney Int. 85 (2014) 103-11. doi:10.1038/ki.2013.328.

[71] H.A.M. Mutsaers, U.F.H. Engelke, M.J.G. Wilmer, J.F.M. Wetzels, R.A. Wevers, L.P. van den Heuvel, J.G. Hoenderop, R. Masereeuw, Optimized Metabolomic Approach to Identify Uremic Solutes in Plasma of Stage 3-4 Chronic Kidney Disease Patients, PLoS One. 8 (2013) e71199. doi:10.1371/journal.pone.0071199.

[72] J.R. Stubbs, J.A. House, A.J. Ocque, S. Zhang, C. Johnson, C. Kimber, K. Schmidt, A. Gupta, J.B. Wetmore, T.D. Nolin, J.A. Spertus, A.S. Yu, Serum Trimethylamine-N-Oxide is Elevated in CKD and Correlates with Coronary Atherosclerosis Burden, J. Am. Soc. Nephrol. (2015) ASN.2014111063. doi:10.1681/ASN.2014111063.

[73] T. Toyohara, Y. Akiyama, T. Suzuki, Y. Takeuchi, E. Mishima, M. Tanemoto, A. Momose, N. Toki, H. Sato, M. Nakayama, A. Hozawa, I. Tsuji, S. Ito, T. Soga, T. Abe, Metabolomic profiling of uremic solutes in CKD patients, Hypertens Res. 33 (2010) 944-952. doi:10.1038/hr.2010.113.

[74] B. Yu, Y. Zheng, J.A. Nettleton, D. Alexander, J. Coresh, E. Boerwinkle, Serum metabolomic profiling and incident CKD among African Americans., Clin. J. Am. Soc. Nephrol. 9 (2014) 14101417. doi:10.2215/CJN.11971113.

[75] P. Sekula, O.-N. Goek, L. Quaye, C. Barrios, A.S. Levey, W. Romisch-Margl, C. Menni, I. Yet, C. Gieger, L.A. Inker, J. Adamski, W. Gronwald, T. Illig, K. Dettmer, J. Krumsiek, P.J. Oefner, A.M. Valdes, C. Meisinger, J. Coresh, T.D. Spector, R.P. Mohney, K. Suhre, G. Kastenmuller, A. Kottgen, A Metabolome-Wide Association Study of Kidney Function and Disease in the General Population, J. Am. Soc. Nephrol. 27 (2016) 1175-1188. doi:10.1681/ASN.2014111099.

[76] S. Kalim, C.B. Clish, J. Wenger, S. Elmariah, R.W. Yeh, J.J. Deferio, K. Pierce, A. Deik, R.E. Gerszten, R. Thadhani, E.P. Rhee, A Plasma Long-Chain Acylcarnitine Predicts Cardiovascular Mortality in Incident Dialysis Patients, J. Am. Heart Assoc. 2 (2013) e000542-e000542. doi:10.1161/JAHA.113.000542.

[77] O.-N. Goek, A. Döring, C. Gieger, M. Heier, W. Koenig, C. Prehn, W. Römisch-Margl, R. Wang- 
Sattler, T. Illig, K. Suhre, P. Sekula, G. Zhai, J. Adamski, A. Köttgen, C. Meisinger, Serum Metabolite Concentrations and Decreased GFR in the General Population, Am. J. Kidney Dis. 60 (2012) 197-206. doi:10.1053/j.ajkd.2012.01.014.

[78] C.-J. Lin, H.-H. Chen, C.-F. Pan, C.-K. Chuang, T.-J. Wang, F.-J. Sun, C.-J. Wu, p-cresylsulfate and indoxyl sulfate level at different stages of chronic kidney disease, J. Clin. Lab. Anal. 25 (2011) 191-197. doi:10.1002/jcla.20456.

[79] S. Qi, X. Ouyang, L. Wang, W. Peng, J. Wen, Y. Dai, A Pilot Metabolic Profiling Study in Serum of Patients with Chronic Kidney Disease Based on $1 \mathrm{H}-\mathrm{NMR}-S p e c t r o s c o p y$, Clin. Transl. Sci. 5 (2012) 379-385. doi:10.1111/j.1752-8062.2012.00437.x.

[80] T. Kimura, K. Yasuda, R. Yamamoto, T. Soga, H. Rakugi, T. Hayashi, Y. Isaka, Identification of biomarkers for development of end-stage kidney disease in chronic kidney disease by metabolomic profiling., Sci. Rep. 6 (2016) 26138. doi:10.1038/srep26138.

[81] E.P. Rhee, J.E. Ho, M.-H. Chen, D. Shen, S. Cheng, M.G. Larson, A. Ghorbani, X. Shi, I.T. Helenius, C.J. O’Donnell, A.L. Souza, A. Deik, K.A. Pierce, K. Bullock, G.A. Walford, R.S. Vasan, J.C. Florez, C. Clish, J.-R.J. Yeh, T.J. Wang, R.E. Gerszten, A genome-wide association study of the human metabolome in a community-based cohort., Cell Metab. 18 (2013) 130-43. doi:10.1016/j.cmet.2013.06.013.

[82] K. Suhre, H. Wallaschofski, J. Raffler, N. Friedrich, R. Haring, K. Michael, C. Wasner, A. Krebs, F. Kronenberg, D. Chang, C. Meisinger, H.-E. Wichmann, W. Hoffmann, H. Völzke, U. Völker, A. Teumer, R. Biffar, T. Kocher, S.B. Felix, T. Illig, H.K. Kroemer, C. Gieger, W. Römisch-Margl, M. Nauck, A genome-wide association study of metabolic traits in human urine, Nat. Genet. 43 (2011) 565-569. doi:10.1038/ng.837.

[83] A. Mattoo, D.S. Goldfarb, Cystinuria., Semin. Nephrol. 28 (2008) 181-91. doi:10.1016/j.semnephrol.2008.01.011.

[84] J.C. Chambers, W. Zhang, G.M. Lord, P. van der Harst, D.A. Lawlor, J.S. Sehmi, D.P. Gale, M.N. Wass, K.R. Ahmadi, S.J.L. Bakker, J. Beckmann, H.J.G. Bilo, M. Bochud, M.J. Brown, M.J. Caulfield, J.M.C. Connell, H.T. Cook, I. Cotlarciuc, G. Davey Smith, R. de Silva, G. Deng, O. Devuyst, L.D. Dikkeschei, N. Dimkovic, M. Dockrell, A. Dominiczak, S. Ebrahim, T. Eggermann, M. Farrall, L. Ferrucci, J. Floege, N.G. Forouhi, R.T. Gansevoort, X. Han, B. Hedblad, J.J. Homan van der Heide, B.G. Hepkema, M. Hernandez-Fuentes, E. Hypponen, T. Johnson, P.E. de Jong, N. Kleefstra, V. Lagou, M. Lapsley, Y. Li, R.J.F. Loos, J. Luan, K. Luttropp, C. Maréchal, O. Melander, P.B. Munroe, L. Nordfors, A. Parsa, L. Peltonen, B.W. Penninx, E. Perucha, A. Pouta, I. Prokopenko, P.J. Roderick, A. Ruokonen, N.J. Samani, S. Sanna, M. Schalling, D. Schlessinger, G. Schlieper, M.A.J. Seelen, A.R. Shuldiner, M. Sjögren, J.H. Smit, H. Snieder, N. Soranzo, T.D. Spector, P. Stenvinkel, M.J.E. Sternberg, R. Swaminathan, T. Tanaka, L.J. Ubink-Veltmaat, M. Uda, P. Vollenweider, C. Wallace, D. Waterworth, K. Zerres, G. Waeber, N.J. Wareham, P.H. Maxwell, M.I. McCarthy, M.-R. Jarvelin, V. Mooser, G.R. Abecasis, L. Lightstone, J. Scott, G. Navis, P. Elliott, J.S. Kooner, Genetic loci influencing kidney function and chronic kidney disease., Nat. Genet. 42 (2010) 373-5. doi:10.1038/ng.566.

[85] C. Zhu, Q. Liang, P. Hu, Y. Wang, G. Luo, Phospholipidomic identification of potential plasma biomarkers associated with type 2 diabetes mellitus and diabetic nephropathy, Talanta. 85 (2011) 1711-1720. doi:10.1016/j.talanta.2011.05.036.

[86] L. PANG, Q. LIANG, Y. WANG, L. PING, G. LUO, Simultaneous determination and quantification of seven major phospholipid classes in human blood using normal-phase liquid chromatography coupled with electrospray mass spectrometry and the application in diabetes nephropathy, J. Chromatogr. B. 869 (2008) 118-125. doi:10.1016/j.jchromb.2008.05.027. 
[87] V.-P. Mäkinen, P. Soininen, C. Forsblom, M. Parkkonen, P. Ingman, K. Kaski, P.-H. Groop, M. Ala-Korpela, FinnDiane Study Group, Diagnosing diabetic nephropathy by $1 \mathrm{H}$ NMR metabonomics of serum., MAGMA. 19 (2006) 281-96. doi:10.1007/s10334-006-0054-y.

[88] M.J. Pena, H.J. Lambers Heerspink, M.E. Hellemons, T. Friedrich, G. Dallmann, M. Lajer, S.J.L. Bakker, R.T. Gansevoort, P. Rossing, D. de Zeeuw, S.S. Roscioni, Urine and plasma metabolites predict the development of diabetic nephropathy in individuals with Type 2 diabetes mellitus., Diabet. Med. 31 (2014) 1138-47. doi:10.1111/dme.12447.

[89] V. Sirolli, C. Rossi, A. Di Castelnuovo, P. Felaco, L. Amoroso, M. Zucchelli, D. Ciavardelli, C. Di Ilio, P. Sacchetta, S. Bernardini, A. Arduini, M. Bonomini, A. Urbani, Toward personalized hemodialysis by low molecular weight amino-containing compounds: future perspective of patient metabolic fingerprint., Blood Transfus. 10 Suppl 2 (2012) s78-88. doi:10.2450/2012.012S.

[90] J. Zhang, L. Yan, W. Chen, L. Lin, X. Song, X. Yan, W. Hang, B. Huang, Metabonomics research of diabetic nephropathy and type 2 diabetes mellitus based on UPLC-oaTOF-MS system., Anal. Chim. Acta. 650 (2009) 16-22. doi:10.1016/j.aca.2009.02.027.

[91] A. Hirayama, E. Nakashima, M. Sugimoto, S. Akiyama, W. Sato, S. Maruyama, S. Matsuo, M. Tomita, Y. Yuzawa, T. Soga, Metabolic profiling reveals new serum biomarkers for differentiating diabetic nephropathy, Anal. Bioanal. Chem. 404 (2012) 3101-3109. doi:10.1007/s00216-012-6412-x.

[92] L.-D. Han, J.-F. Xia, Q.-L. Liang, Y. Wang, Y.-M. Wang, P. Hu, P. Li, G.-A. Luo, Plasma esterified and non-esterified fatty acids metabolic profiling using gas chromatography-mass spectrometry and its application in the study of diabetic mellitus and diabetic nephropathy, Anal. Chim. Acta. 689 (2011) 85-91. doi:10.1016/j.aca.2011.01.034.

[93] K. Sharma, B. Karl, A. V. Mathew, J.A. Gangoiti, C.L. Wassel, R. Saito, M. Pu, S. Sharma, Y.-H. You, L. Wang, M. Diamond-Stanic, M.T. Lindenmeyer, C. Forsblom, W. Wu, J.H. Ix, T. Ideker, J.B. Kopp, S.K. Nigam, C.D. Cohen, P.-H. Groop, B.A. Barshop, L. Natarajan, W.L. Nyhan, R.K. Naviaux, Metabolomics Reveals Signature of Mitochondrial Dysfunction in Diabetic Kidney Disease, J. Am. Soc. Nephrol. 24 (2013) 1901-1912. doi:10.1681/ASN.2013020126.

[94] J.-F. Xia, Q.-L. Liang, X.-P. Liang, Y.-M. Wang, P. Hu, P. Li, G.-A. Luo, Ultraviolet and tandem mass spectrometry for simultaneous quantification of 21 pivotal metabolites in plasma from patients with diabetic nephropathy, J. Chromatogr. B. 877 (2009) 1930-1936. doi:10.1016/j.jchromb.2009.05.047.

[95] J.-F. Xia, Q.-L. Liang, P. Hu, Y.-M. Wang, P. Li, G.-A. Luo, Correlations of six related purine metabolites and diabetic nephropathy in Chinese type 2 diabetic patients., Clin. Biochem. 42 (2009) 215-20. doi:10.1016/j.clinbiochem.2008.10.009.

[96] Z. Jiang, Q. Liang, G. Luo, P. Hu, P. Li, Y. Wang, HPLC-electrospray tandem mass spectrometry for simultaneous quantitation of eight plasma aminothiols: application to studies of diabetic nephropathy., Talanta. 77 (2009) 1279-84. doi:10.1016/j.talanta.2008.08.031.

[97] M.A. Niewczas, T.L. Sirich, A. V. Mathew, J. Skupien, R.P. Mohney, J.H. Warram, A. Smiles, X. Huang, W. Walker, J. Byun, E.D. Karoly, E.M. Kensicki, G.T. Berry, J. V. Bonventre, S. Pennathur, T.W. Meyer, A.S. Krolewski, Uremic solutes and risk of end-stage renal disease in type 2 diabetes: metabolomic study, Kidney Int. 85 (2014) 1214-1224. doi:10.1038/ki.2013.497.

[98] A. Solini, M.L. Manca, G. Penno, G. Pugliese, J.E. Cobb, E. Ferrannini, Prediction of Declining Renal Function and Albuminuria in Patients With Type 2 Diabetes by Metabolomics, J. Clin. Endocrinol. Metab. 101 (2016) 696-704. doi:10.1210/jc.2015-3345. 
[99] J.-E. Lee, Y.H. Lee, S.-Y. Kim, Y.G. Kim, J.-Y. Moon, K.-H. Jeong, T.W. Lee, C.-G. Ihm, S. Kim, K.H. Kim, D.K. Kim, Y.S. Kim, C.-D. Kim, C.W. Park, D.Y. Lee, S.-H. Lee, Systematic biomarker discovery and coordinative validation for different primary nephrotic syndromes using gas chromatography-mass spectrometry., J. Chromatogr. A. 1453 (2016) 105-115. doi:10.1016/j.chroma.2016.05.058.

[100] X. Hao, X. Liu, W. Wang, H. Ren, J. Xie, P. Shen, D. Lin, N. Chen, Distinct Metabolic Profile of Primary Focal Segmental Glomerulosclerosis Revealed by NMR-Based Metabolomics, PLoS One. 8 (2013) e78531. doi:10.1371/journal.pone.0078531.

[101] X. Gao, W. Chen, R. Li, M. Wang, C. Chen, R. Zeng, Y. Deng, Systematic variations associated with renal disease uncovered by parallel metabolomics of urine and serum, BMC Syst. Biol. 6 (2012) S14. doi:10.1186/1752-0509-6-S1-S14.

[102] W. Sui, L. Li, W. Che, Z. Guimai, J. Chen, W. Li, Y. Dai, A proton nuclear magnetic resonancebased metabonomics study of metabolic profiling in immunoglobulin a nephropathy., Clinics (Sao Paulo). 67 (2012) 363-73.

[103] A.A. Bengtsson, J. Trygg, D.M. Wuttge, G. Sturfelt, E. Theander, M. Donten, T. Moritz, C.-J. Sennbro, F. Torell, C. Lood, I. Surowiec, S. Rännar, T. Lundstedt, Metabolic Profiling of Systemic Lupus Erythematosus and Comparison with Primary Sjögren's Syndrome and Systemic Sclerosis, PLoS One. 11 (2016) e0159384. doi:10.1371/journal.pone.0159384.

[104] L.E. Romick-Rosendale, H.I. Brunner, M.R. Bennett, R. Mina, S. Nelson, M. Petri, A. Kiani, P. Devarajan, M.A. Kennedy, Identification of urinary metabolites that distinguish membranous lupus nephritis from proliferative lupus nephritis and focal segmental glomerulosclerosis, Arthritis Res. Ther. 13 (2011) R199. doi:10.1186/ar3530.

[105] Q. Wu, X. Lai, Z. Zhu, Z. Hong, X. Dong, T. Wang, H. Wang, Z. Lou, Q. Lin, Z. Guo, Y. Chai, Evidence for Chronic Kidney Disease-Mineral and Bone Disorder Associated With Metabolic Pathway Changes, Medicine (Baltimore). 94 (2015) e1273. doi:10.1097/MD.0000000000001273.

[106] D. Wang, S. Strandgaard, M.L. Borresen, Z. Luo, S.G. Connors, Q. Yan, C.S. Wilcox, Asymmetric dimethylarginine and lipid peroxidation products in early autosomal dominant polycystic kidney disease., Am. J. Kidney Dis. 51 (2008) 184-91. doi:10.1053/j.ajkd.2007.09.020.

[107] J. Wang, Y. Zhou, M. Xu, R. Rong, Y. Guo, T. Zhu, Urinary Metabolomics in Monitoring Acute Tubular Injury of Renal Allografts: A Preliminary Report, Transplant. Proc. 43 (2011) 37383742. doi:10.1016/j.transproceed.2011.08.109. 